Research Article

\title{
Three-Dimensional, Real-Time, and Intelligent Data Acquisition of Large Deformation in Deep Tunnels
}

\author{
Yue-Mao Zhao $\mathbb{D D}^{1},{ }^{1}$ Yong Han $\left(\mathbb{D},{ }^{1}\right.$ Yong-Yuan Kou $\mathbb{D},{ }^{2}$ Lin Li $\mathbb{D}^{3},{ }^{3}$ and Jiu-Hua Du $\mathbb{D}^{3}$ \\ ${ }^{1}$ Key Laboratory of Ministry of Education on Safe Mining of Deep Metal Mines, Northeastern University, \\ Shenyang, 110819, China \\ ${ }^{2}$ Jinchuan Group Co., Ltd., Jinchang 737100, China \\ ${ }^{3}$ ZhongKuang Gold Industry Stock Co., Ltd., Yantai 265400, China \\ Correspondence should be addressed to Yue-Mao Zhao; 1510456@stu.neu.edu.cn
}

Received 14 December 2020; Revised 25 December 2020; Accepted 31 December 2020; Published 15 January 2021

Academic Editor: Gong-Da Wang

Copyright (c) 2021 Yue-Mao Zhao et al. This is an open access article distributed under the Creative Commons Attribution License, which permits unrestricted use, distribution, and reproduction in any medium, provided the original work is properly cited.

\begin{abstract}
Potential disasters of large deformation pose serious threats to deep underground projects such as tunnels and mines. Engineering with large deformation is typically characterized by high stress, complex engineering geology, strong disturbance, and squeezing deformation, posing a great challenge to the design of an effective and accurate monitoring system. To address this problem, it is necessary to grasp the three-dimensional features of deformation and establish integrated monitoring of a support system. Monitoring equipment should be selected to obtain joint, stress, deformation, cracking process, and other information, and this information can be fed back to the warning and control module. The scheme of the monitoring system presented here was successfully applied to a deep metal mine. This intelligent monitoring system ensures safety during the construction and operation of the tunnel under complex surrounding rock conditions, allows the use of field monitoring data to guide construction and design, and provides a reference for future construction and project monitoring.
\end{abstract}

\section{Introduction}

With the rapid development of the world economy, easily accessible resources have been nearly exhausted and resource exploitation requires deep excavation. Deep engineering is also required for many road and rail tunnels that cut through huge mountains and are buried thousands of meters deep. The engineering environment is significantly different for deep and shallow engineering, and deep projects present unique engineering problems with poorly understood mechanisms [1-3]. In exploitation and utilization of underground resources, outburst-rockburst, large deformation, and other disasters are the threats of deep mining [4]. Under the influence of mining disturbance, the coupling effect of high ground stress, high gas pressure, and low permeability is stronger [5].

Tunnels under the conditions of high geostress, excavation disturbance, and weak engineering geology may encounter problems such as collapse, spalling, and large extrusion deformation [6]. This study focused on large deformation during the construction period of deep underground engineering. Large deformation refers to the support system of surrounding rock displacement in the radial direction after tunnel excavation under high ground pressure. Large deformation occurs when the displacement of the squeezing deformation exceeds the conventional deformation of the surrounding rock [7].

Given the unique challenges of deep underground engineering, monitoring is typically performed in real time and using systematic features that can be used to assess squeezing during the construction and service periods [8]. The formation mechanism of large deformation remains a complex problem, as reflected in the lack of systematic studies of advanced monitoring of internal fractures of surrounding rock and the lack of three-dimensional (3D) sensing technology of deformation in squeezing tunnel $[9,10]$. Because underground projects may face various potential disaster threats, a monitoring system with an intelligent early warning function is required $[11,12]$. 
With the development of the information age, the development and popularization of sensors, intelligent total station, the Internet, and other technologies has improved engineering monitoring and allow real-time synchronization of monitoring data and monitoring terminals [13-15]. Online synchronization and real-time monitoring are the basis of the Internet of Things [16]. To investigate the large deformation formation mechanism, real-time and systematic data were acquired. Setting up an early warning and evaluation module needs further collection of data and the establishment of an intelligent security monitoring system.

\section{Technical Challenges Facing Jinchuan Mine Monitoring System}

The Jinchuan mine is an extremely large metal mine in China, with deep tunnel large deformation [17]. The tunnels there often traverse complex engineering geological environments, such as fractured hard rock, weak rock, and other materials. The geological structure and mineralization process have created unique unfavorable tunneling conditions making these areas extremely unstable [18]. There is high geostress in a tunnel, especially horizontal tectonic stress. During tunneling, a bolt-net-shotcrete support system is usually adopted, and after the implementation of support, rapid squeezing deformation of the tunnel can occur $[19,20]$.

As shown in Figure 1, there is obvious squeezing deformation on both sides of the tunnel, which tends to tear apart the metal mesh and the shotcrete. The left-sidewall of the tunnel cracked out, with a displacement of about $300 \mathrm{~mm}$. The shotcrete on the right side also crumbled and fell, with extrusion of the metal mesh. The use of a fixed point for surface monitoring is vulnerable to damage, limiting the acquisition of continuous data. If a surface failure occurs, the extent and depth of internal cracking are unknown. Thus, the construction of a three-dimensional, real-time, and intelligent monitoring system is required to reveal the interaction mechanism between support and surrounding rock mass.

The large deformation of the tunnel in the Jinchuan mine has a large impact range, with annual repair costs as high as hundreds of millions of yuan [17]. This mine transport roadway has been in service for more than five years and there are often problems with large deformation. After several repairs, the deformation often converges and the rheology continues for a period, exhibiting significant accumulation. At intervals of $10 \mathrm{~m}$ along the tunnel axis, the convergence value of the section was roughly calculated for deformation of about $0.6 \mathrm{~m}-1.3 \mathrm{~m}$. The calculations are shown in Figure 2. Given the magnitude of this problem, it is urgent to explore the mechanism of large deformation to find a reasonable control technique.

To ensure tunnel safety, there has been extensive monitoring in this mine since 1970, with monitoring techniques including surface settlement, measurement of ground pressure, observation of convergence deformation, and observation of displacement in the surrounding rock [18]. Monitoring equipment [19-21] adopted in the tunnel

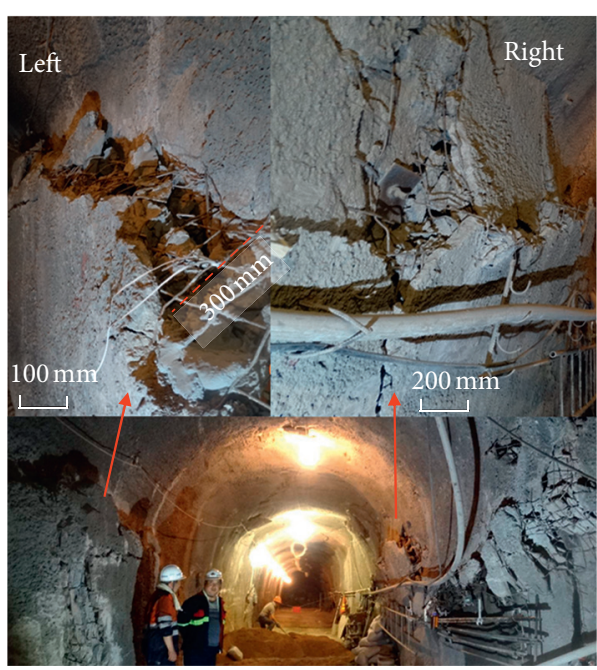

FIgURE 1: Large area of extrusion cracking on the sidewall of the deep tunnel.

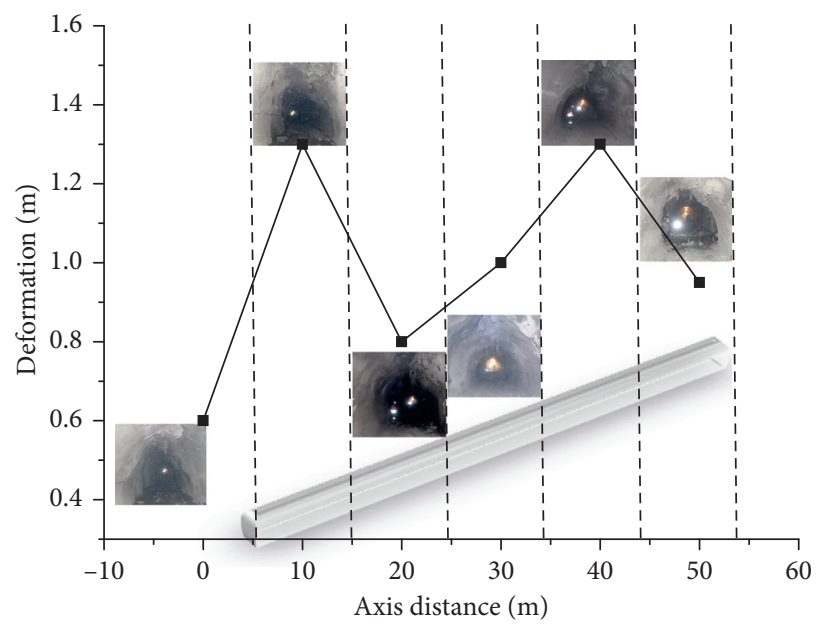

FIgure 2: Convergence deformation along the axis section of the tunnel.

includes (1) steel ruler, convergence gauge, laser rangefinder, and other tools to monitor surface convergence deformation; (2) extensometer, multipoint displacement gauges, acoustic emission, and other devices to monitor the internal cracking and deformation of deep surrounding rock; (3) fiber Bragg grating (FBG) information fusion to measure the deformation of surrounding rock. Although much information has been acquired, these monitoring systems cannot acquire and process data in real time and cannot intelligently select useful information for decision-making.

\section{Monitoring System}

3.1. Design of Monitoring System. An intelligent monitoring system was designed to monitor the process of large deformation. The system consists of several modules for monitoring, data storage and transmission, warning, and control. Each module obtains, stores, and analyzes data for its design objectives. As shown in Figure 3(a), the three 


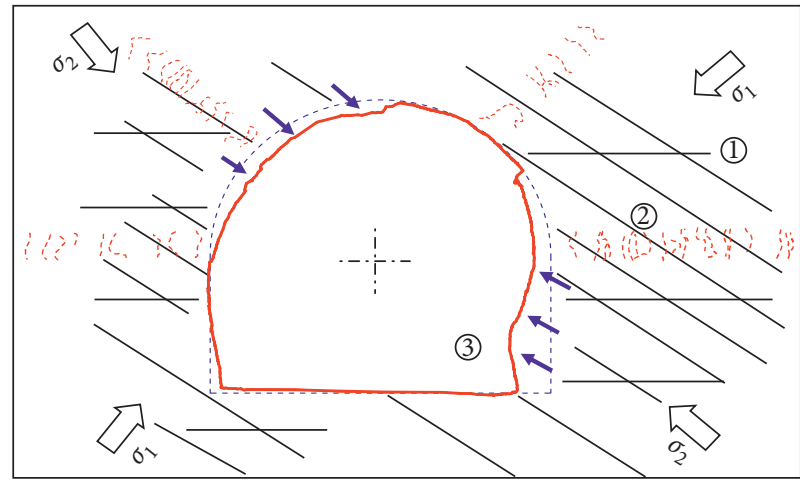

(a)

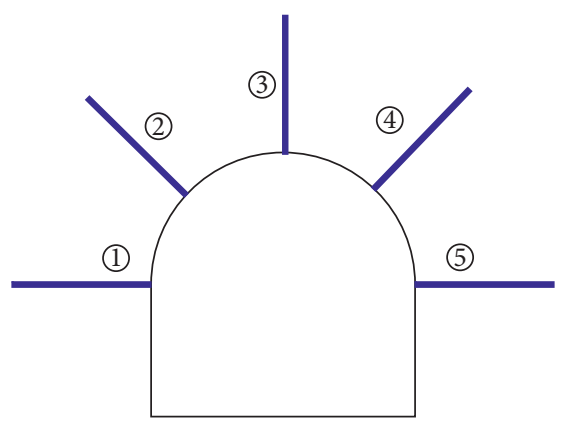

(b)

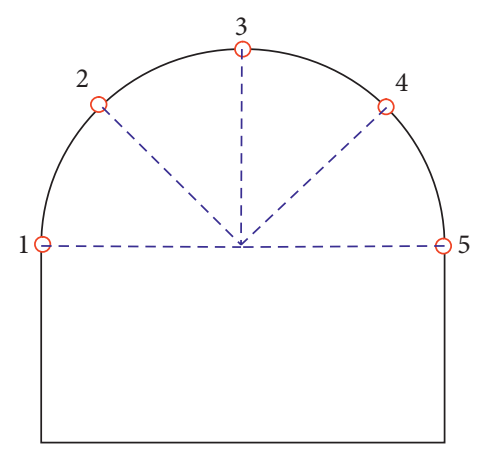

(c)

FiguRE 3: Basic principle of large deformation measurement in the tunnel. (a) Major aspects of large deformation, (b) boreholes to measure information in the surrounding rock, and (c) monitoring points on the tunnel surface.

major aspects of large deformation are characteristics of engineering geology, internal cracking of surrounding rocks, and surface deformation. As shown in Figure 3(b), a borehole is usually adopted to measure the interior of the surrounding rock in fine detail, with a measurement accuracy of millimeters. The cracking depth and degree can be determined by observing the cracking evolution process in the surrounding rock with a borehole camera. As shown in Figure 3(c), the tunnel surface can be measured by a laser point cloud, with a measurement accuracy of millimeters.

During large deformation, the surface and interior of the surrounding rock will show some mechanical behaviors, requiring comprehensive observation. As shown in Figure 4, the basic data of rock mechanics, joints, and water should be obtained first. Next, the setting of the monitoring system should consider characteristics of the deformation and cracking occurring inside and on the surface of the tunnel and obtain the stress, strain, pressure, and displacement data. The displacement variables can be obtained by noncontact 3D laser scanning. For evolution observation of the degree and depth of rock cracking, the internal cracking of the surrounding rock can be observed by digital borehole televiewer. In addition, the stress-strain data of internal deformation of rock mass-support can be comprehensively obtained by bolt stress gauge, multipoint displacement gauge, pressure cell, and hollow inclusion stress gauge.

As shown in Figure 5, applying the Internet of Things and cloud computing techniques, an intelligent monitoring system can acquire sensor data; transmit, store, and process these data; and send early warnings. Effective transmission is essential to the real-time application of an intelligent monitoring system. In this design, the wired transmission is adopted to ensure the timeliness and reliability of transmission. The network system consists of data cables, optical cables, data acquisition modules, a switch, a gateway, and other transmission terminal equipment. Multivariate data exists as big data in a cloud platform and can be directly used for disaster warning and control measures.

Using the control platform shown in Figure 6, all the monitoring data can be collected in real time from the sensor equipment, with both automatic and manual acquisition functions. A manual acquisition can be used to collect data for monitoring specific sections as needed with manual control of collection frequency and time. Automatic collection requires the setting of frequency and period for periodic data collection. In addition to the real-time display of monitored data, the control platform allows query, analysis, statistics, graphical display, and other functions. When the warning module reaches a set level of danger, the software platform will make a sound and show a pop-up dialog box, send messages, and automatically increase the cross section of the monitoring frequency. Reasonable control measures from the control module are also suggested.

The study of monitoring data is needed to study the mechanism of large deformation disaster, design control measures, and evaluate control techniques. The support of the network, big data, Internet of Things, and artificial 


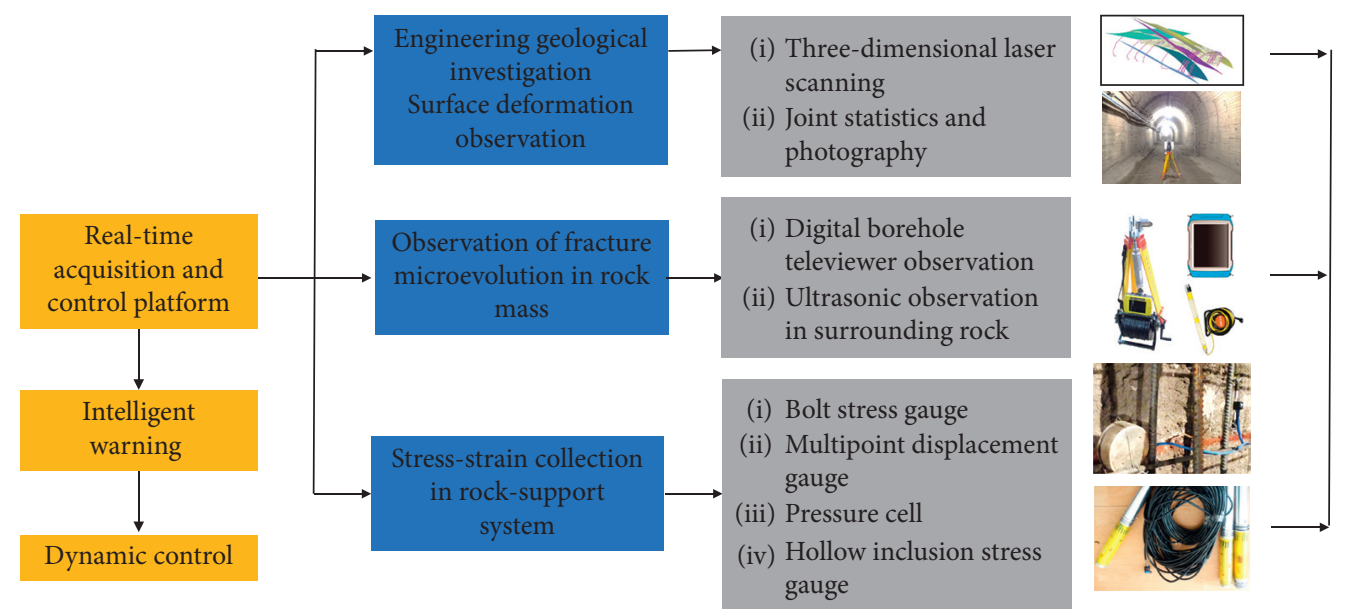

FIGURE 4: Intelligent monitoring system for large deformation.

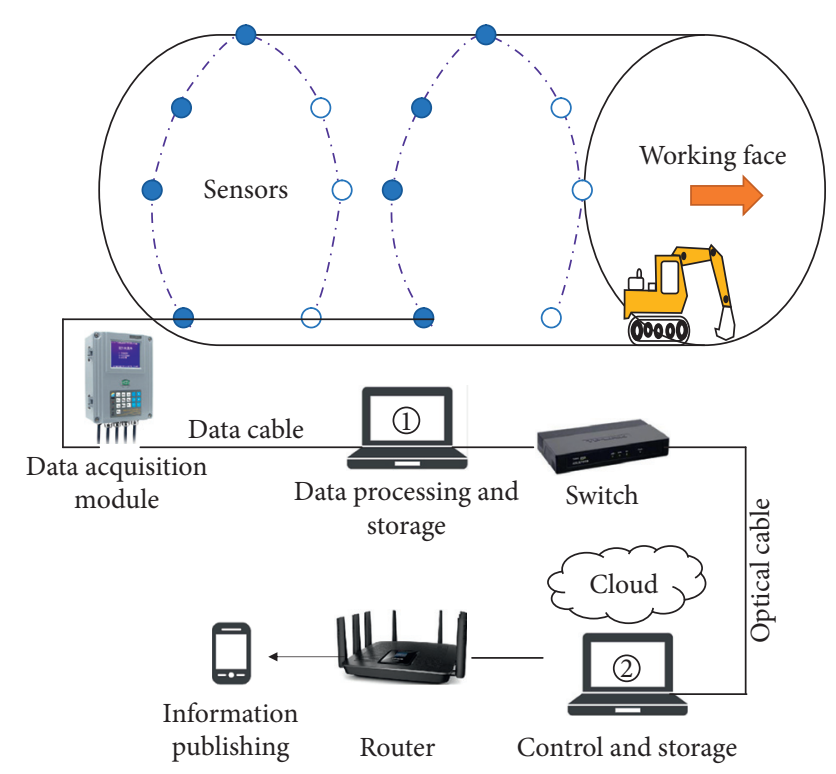

FIgURE 5: Transmission network of the intelligent monitoring system.

intelligence technologies will then be used to further analyze the large deformation disaster mechanism.

3.2. Surface Information Acquisition. Engineering geological survey can determine the geological factors that affect tunnel safety. Preparatory work includes the acquisition of preliminary geological data, tunnel design parameters, and construction data. As shown in Figure 7, site survey to obtain engineering geological information related to tunnel excavation includes working face reconnaissance, joint set statistics, photography, and other data acquisition before each construction cycle. After determining the geological conditions, it is necessary to evaluate the influence and scale of appropriate engineering according to the structure and operation requirements of the tunnel as the basis for ensuring building stability and use.
For surface information acquisition, a three-dimensional (3D) laser scanning system, High-Definition Surveying (HDS), can be used. HDS uses laser ranging to continuously and closely record the three-dimensional coordinates, reflectivity, and texture information of the surface of a target. This system captures data as a point cloud to generate a real three-dimensional record of the space of interest. As shown in Figure 8, this provides point cloud data of engineering surface during construction. The 3D laser scanning equipment consists of a target, scanner, leveling base, bracket, and other components. Field operations require control network establishment, field scanning, and recording measurement. As shown in Figure 9, a single acquisition can obtain tens of meters of high-precision data that can be spliced together to provide data for the whole tunnel along the axis. Using specialized software, 2D or 3D graph, line drawing, point cloud graph, 3D model, and ASCII coordinate data can be output.

After the application of a set of algorithms and data processing methods [10] and sufficient data acquisition, the project profile changes can be obtained. Additionally, the displacement data for key positions can be extracted to obtain a curve of continuous engineering deformation, as shown in Figure 10. Large deformation disaster is characterized by convergence deformation reaching $0.4 \mathrm{~m}$, with serious damage to the support system during excavation. During the service period after lining construction, the deformation rate is slow, but cracking and deformation of the lining must still be monitored.

3.3. Internal Cracking Process of Surrounding Rocks. To assess the failure mechanism of the surrounding rock, a digital borehole televiewer was used to continuously observe the crack. The cracking evolution process at a single location can be sensed by continuous borehole photography. As shown in Figure 11, continuous borehole video is obtained by passing a borehole camera through the borehole and conversion of the video data in the acquisition instrument. Two important indexes are used to assess the evolution of cracking in the surrounding rock [22, 23]: (1) the depth of the maximum cracking area and (2) the degree of cracking in this area. 


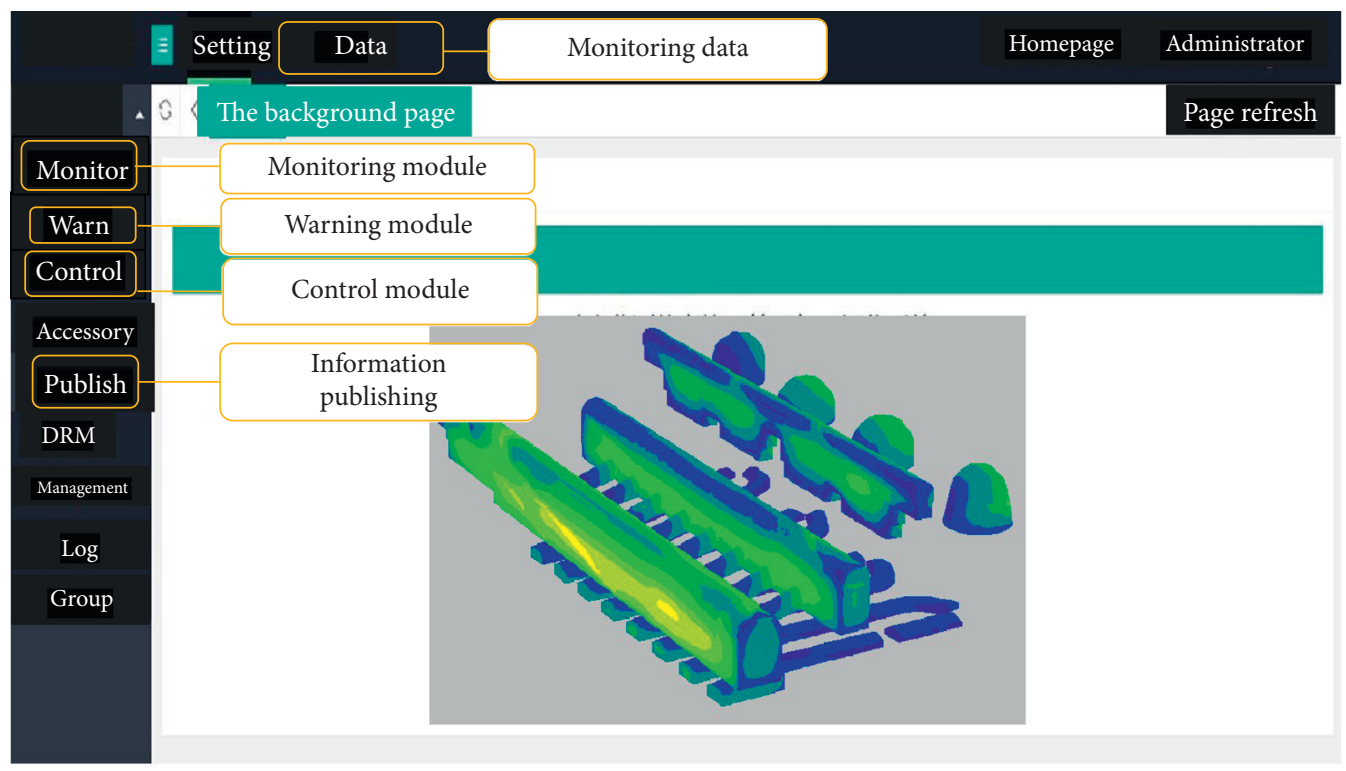

Figure 6: Control platform.

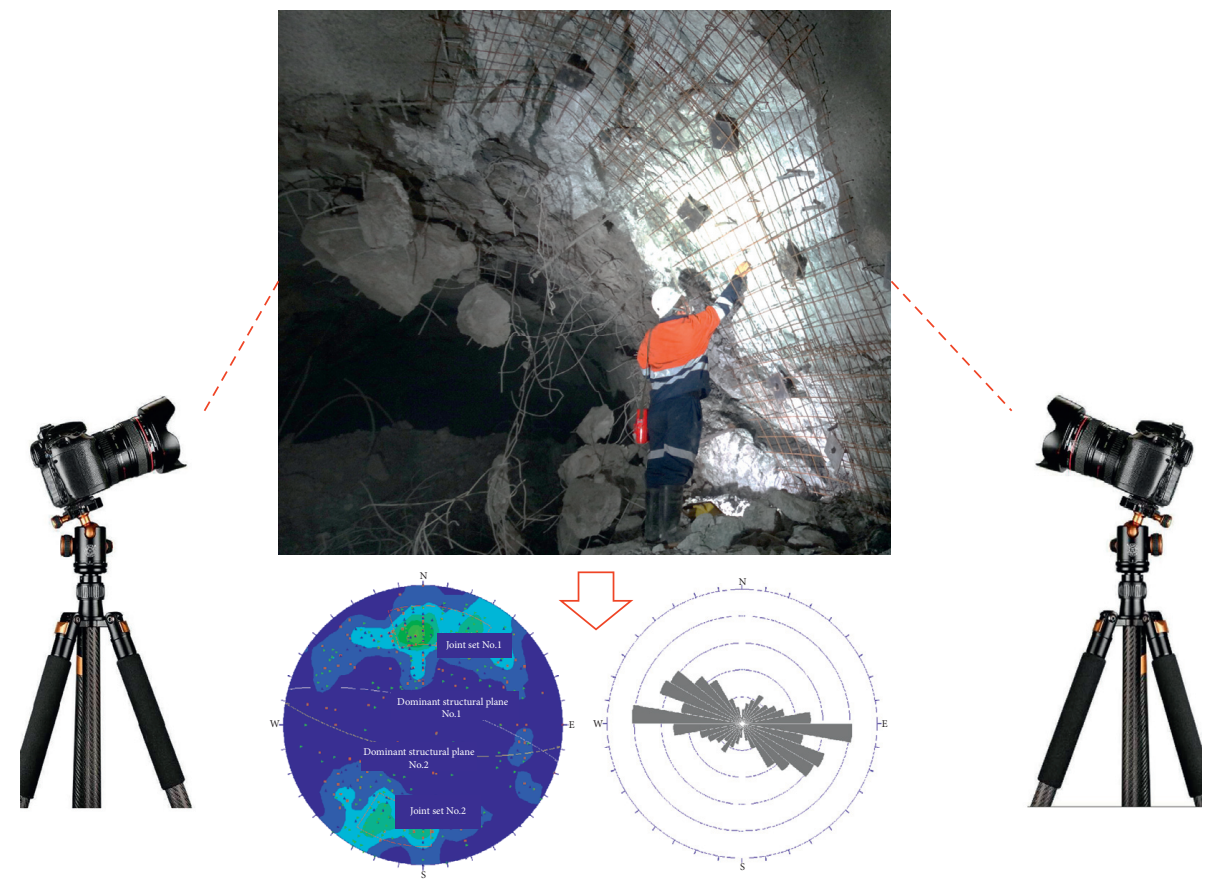

Figure 7: Site reconnaissance of engineering geology.

In the surrounding rock mass, fractures develop in many areas over time. As shown in Figure 12, over almost eight months, the crack width increased from the original $7.2 \mathrm{~mm}$ (position (1) in Figure 8) to $8.4-84 \mathrm{~mm}$ (position (2) in Figure 8, almost 6 months later) and $9.4 \mathrm{~mm}$ (position (3) in Figure 8 , almost 8 months later). In addition, the development of cracks can be accompanied by the initiation of new cracks, which can interlace with old cracks to further degrade the surrounding rock quality.

As shown in Figure 13(a), due to geological conditions, extremely poor rock mass integrity can decrease the stability of a geological borehole, resulting in hole collapse. Even after hole formation, hole collapse may occur due to low stability, excavation disturbance, or blasting vibration (Figure 13(b)). Future work should include the development of in situ geological borehole protection technology to facilitate the study of the adverse geological rock mass.

3.4. Acquisition of Stress-Strain Data in Surrounding Rocks. High-frequency acquisition of internal stress and strain of the rock mass and support system includes bolt stress gauge, multipoint displacement gauges (extensometers), pressure cells, concrete strain gauges (vibrating wire), hollow 


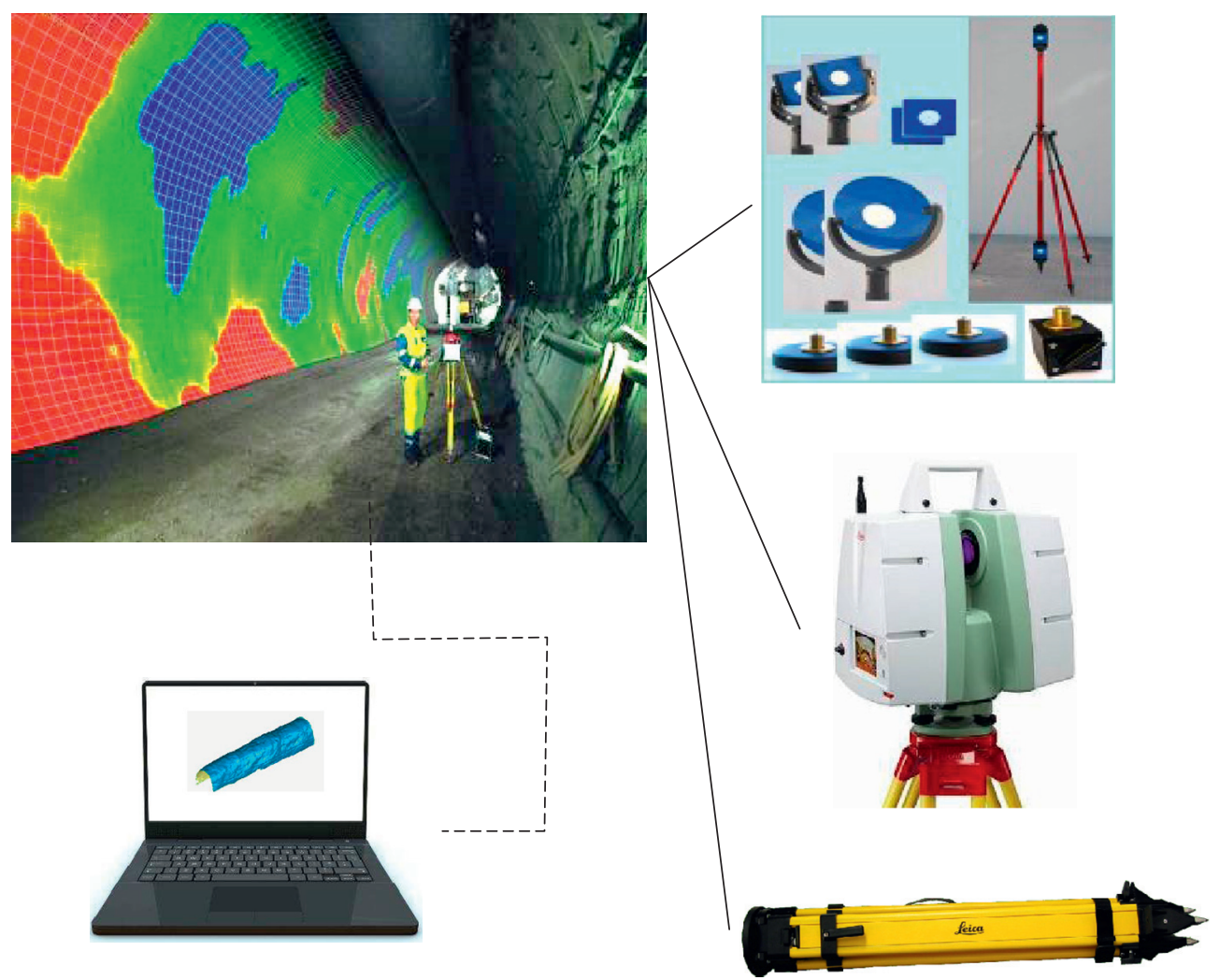

FIGURE 8: Operation of 3D laser scanning equipment.
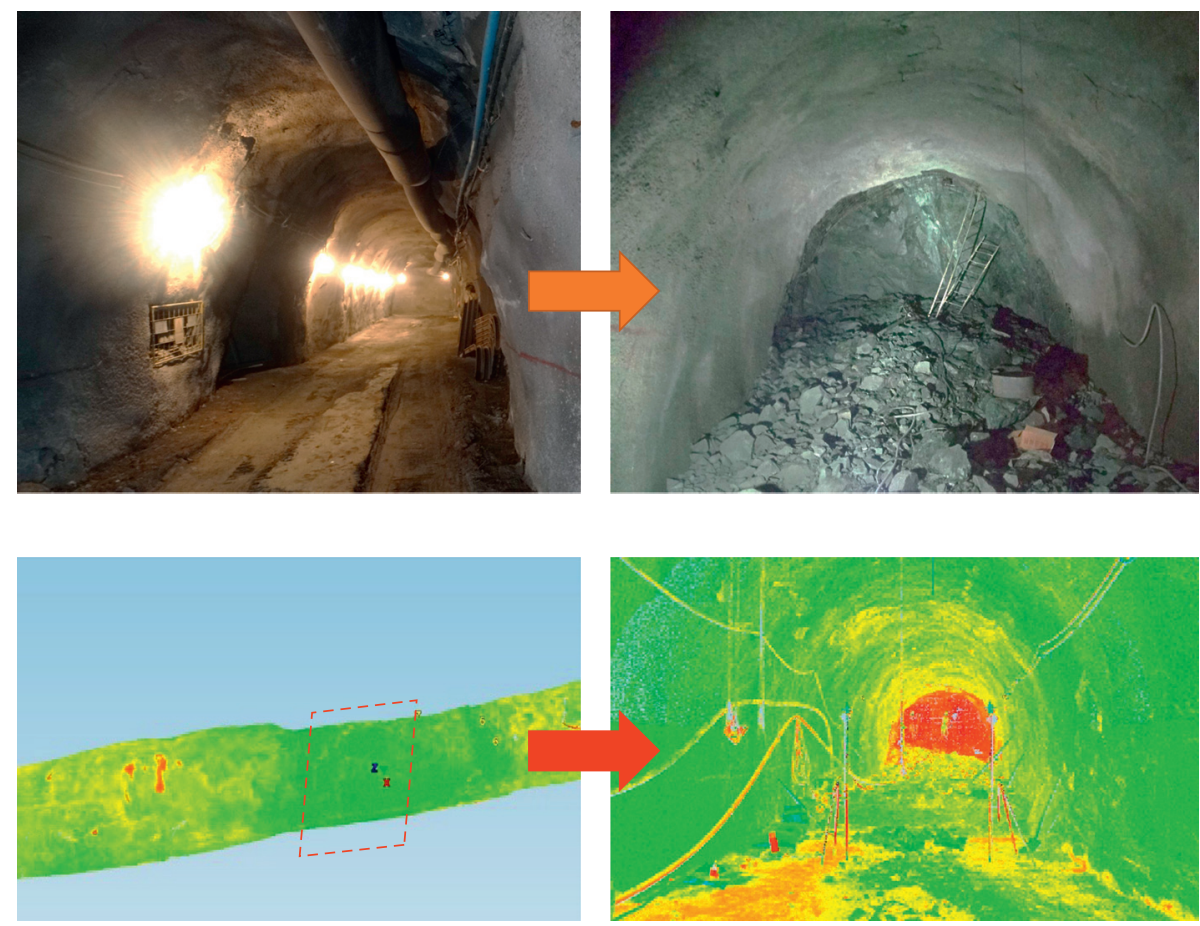

Figure 9: Comparison of the data obtained by real scene photos and 3D laser scanning equipment.

inclusion stress gauges, and other sensing elements. As shown in Table 1, these components are connected as a sensing system. The bolt stress gauge and pressure cell can obtain the mechanical characteristics of both the rock mass and the support system. The data link field operation is shown in Figure 14(a). Sensors are wired to the acquisition module (Figure 14(b)), and the data can be automatically collected by computer control. 


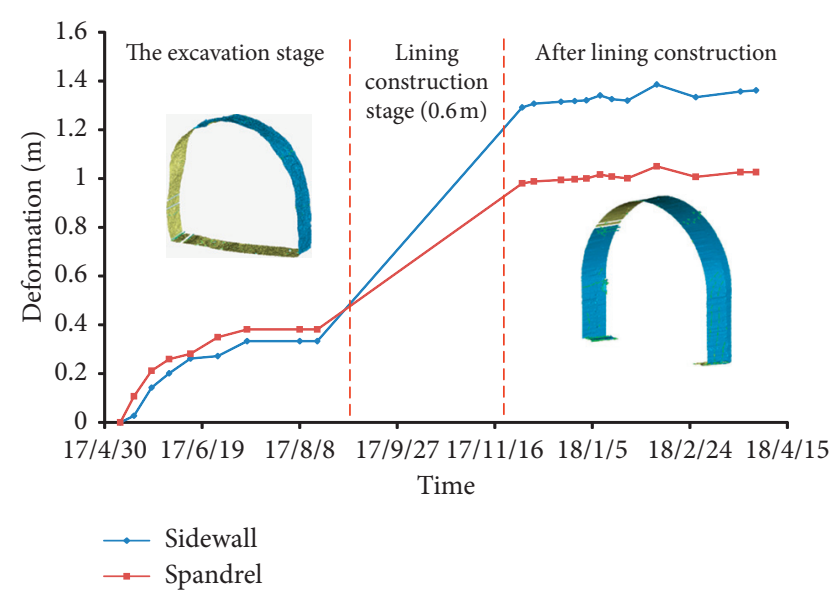

Figure 10: Convergence deformation curve of the tunnel for a typical cross section [10].

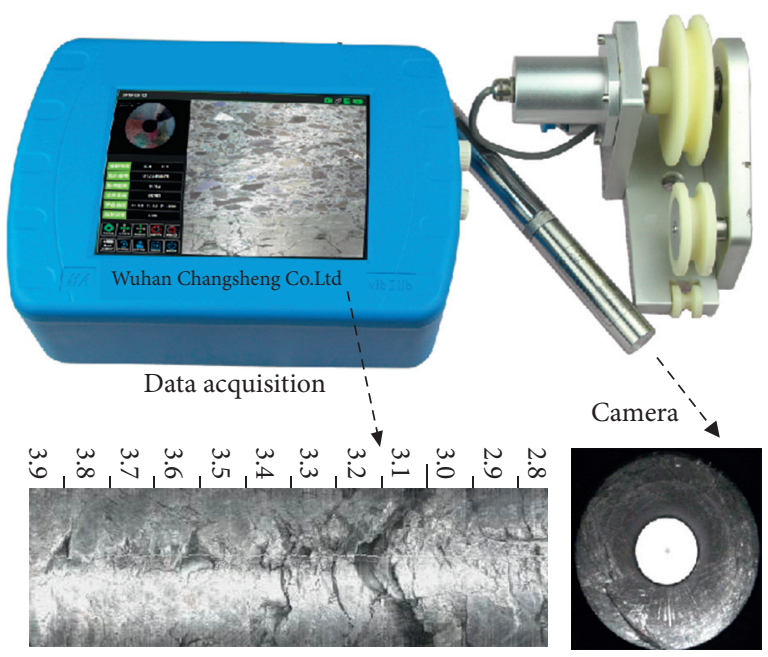

FIGURE 11: Application of drilling camera equipment.

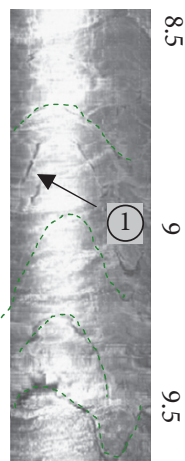

20180418

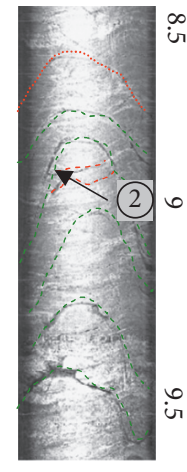

20181012

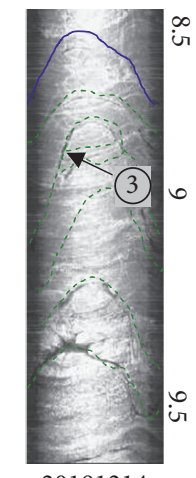

20181214
The crack

Crack initiation

$\sim$ Crack propagation

Figure 12: Continuous observation of cracking process.
Typical data are shown in Figure 15 and constitute a multivariate information system. In multipoint displacement gauge data shown in Figure 15(a), the displacement curve of each measuring point at $3 \mathrm{~m}, 10 \mathrm{~m}$, and $20 \mathrm{~m}$ increased with time. The deformation of the deep measuring point was greater than that of the shallow measuring point in surrounding rocks, and the maximum depth of displacement in the surrounding rock reached $20 \mathrm{~m}$. As shown in Figures 15(c) and 15(d), the stress curves also increased with time and showed a good correlation with the displacement curve data. The pressure cell data in Figure 15(b) also showed significant changes.

\section{Warning and Control of Large Deformation}

4.1. Basic Principles of Early Warning. When a rock mass is overdeformed, there is an increased risk of structural failure such as collapse, large deformation, and surrounding rock instability, which will increase safety risk. With the large deformation of deep tunnel surrounding rock, surrounding rock points can be displaced to the surface, leading to the failure of tunnel structure, including serious deformation of the support structure, lining cracking, and other functional failures. Therefore, it is necessary to construct an early warning system that can detect the initiation of large deformation. Early warning evaluates changes in the surrounding rock mass, the support system, and deformation, described in detail below. As shown in Figure 16, focusing on the interior of the surrounding rock can help identify early signs of the start of large deformation.

(1) Early warning of surrounding rock: as shown in formula (1), a warning is triggered when the cracking depth of surrounding rock $(D)$ is greater than or equal to the length of reinforcement $\left(L_{\text {support }}\right)$. This indicates insufficient control ability of the existing reinforcement (rock bolt or grouting) to the surrounding rock and the possibility that the surrounding rock mass will gradually experience large deformation after excavation under high stress environment. This warning would be based on data from borehole cameras, multipoint displacement gauges, and support design parameters:

$$
D \geq L_{\text {support }}
$$

(2) Early warning of support system: the time-dependent characteristic of large deformation is also reflected in the gradual failure of the support structure. As shown in formula (2), a warning is triggered when the monitoring data of support $\left(M_{\text {support }}\right)$ are greater than or equal to the reasonable index $\left(I_{R}\right)$. This indicates that the existing support system is near the critical value for breaking. The concrete can fail when the bolt stress exceeds the yield point, the lining pressure exceeds the reasonable value, and the concrete stress exceeds the reasonable value. The reasonable index can refer to an engineering design guide and relevant literature. These data can be 


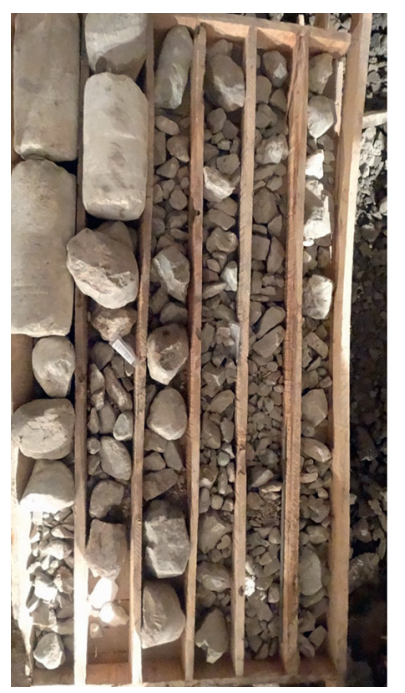

(a)

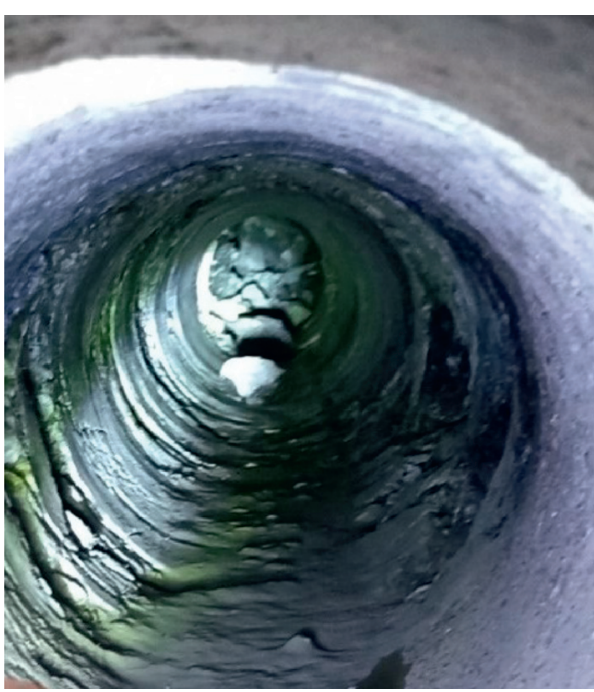

(b)

Figure 13: Collapse of borehole. (a) Broken core and (b) caving of borehole.

TABLE 1: Multiple sensing elements of rock mass-support system.

\begin{tabular}{lcc}
\hline Name & The main parameters & Target \\
\hline Multipoint displacement gauge & Number, range, sensitivity & Displacement of rock mass at different depths \\
Bolt (reinforcement) stress gauge & Range, sensitivity & Variation of stress \\
Pressure cell & Range, sensitivity & Change of pressure between shotcrete and lining \\
Hollow inclusion stress gauge & Range, sensitivity & Change of stress in the rock mass \\
\hline
\end{tabular}

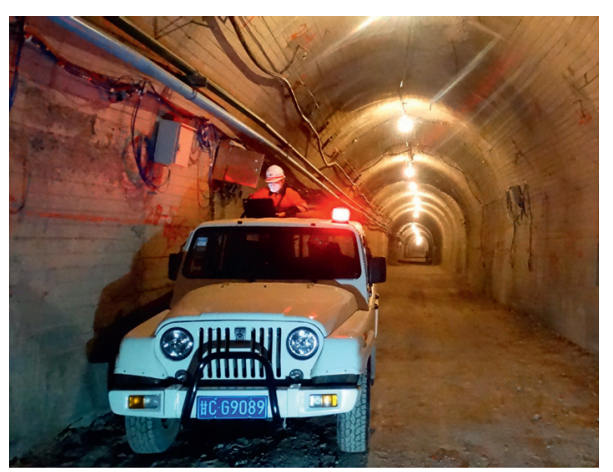

(a)

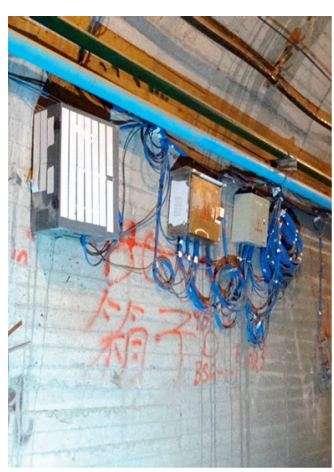

(b)

FIGURE 14: Data connection of field equipment. (a) Data link field operation and (b) data acquisition module.

obtained from the bolt stress gauge, pressure cell, and steel bar gauge:

$$
M_{\text {support }} \geq I_{R}
$$

(3) Early warning of deformation: if the size of the tunnel section cannot meet the design requirements, early remedial action may be required. As shown in formula (3), this criterion is based on the relationship between the convergence deformation $\left(C_{f}\right)$, the limit of section size $\left(L_{0}\right)$ used in the tunnel, and the initial section size $\left(L_{i}\right)$ after excavation. When the on-site monitoring data of displacement reach this condition, the convergence deformation is too large, and the existing support cannot effectively control the surrounding rock and meet its use function. Thus, it is necessary to carry out engineering reinforcement and treatment:

$$
C_{f} \geq L_{i}-L_{0} .
$$

4.2. Dynamic Control of Large Deformation. The early warning module can guide dynamic regulation, as shown in Figure 17, by optimizing the parameters of the excavation process, support system, and support timing. This requires the use of monitoring data to calculate the analysis parameters. 


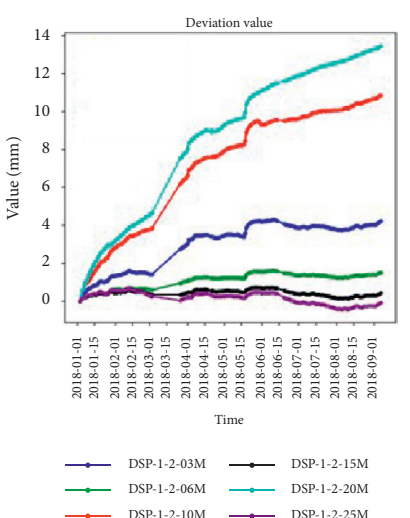

(a)

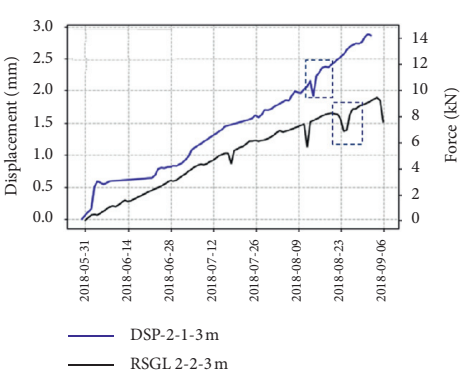

(c)
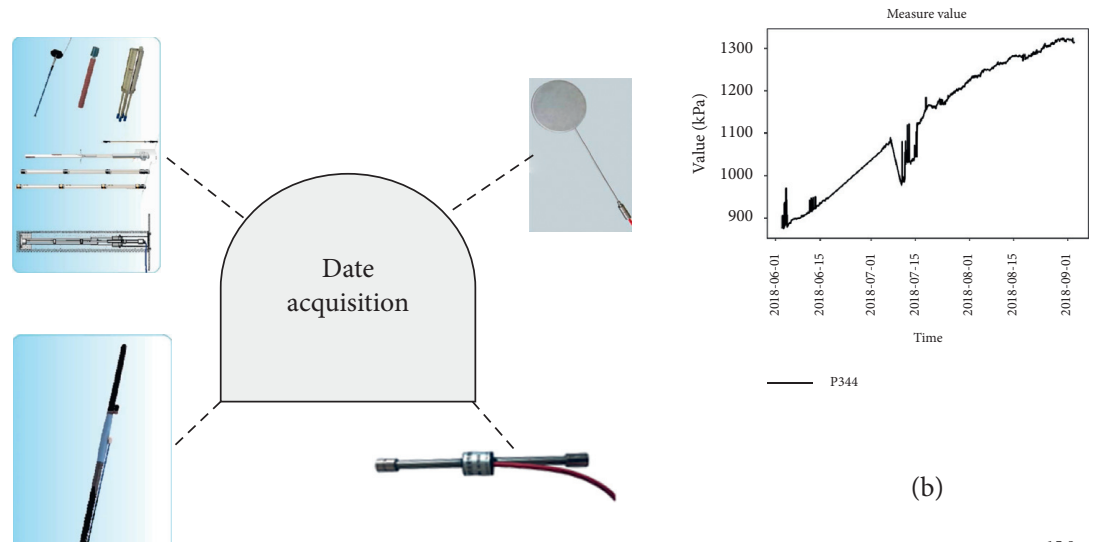

(b)

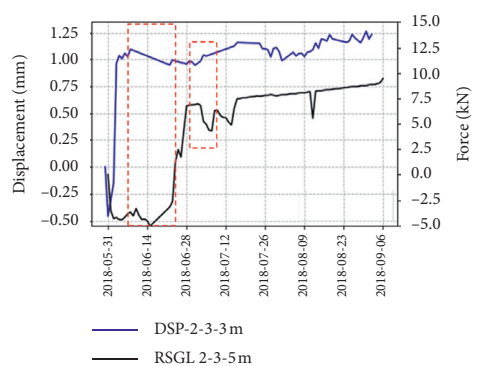

(d)

Figure 15: Multivariate data collection [10]. (a) Multipoint displacement gauge. (b) Pressure cell. (c) Bolt stress gauge. (d) Reinforcement stress gauge.

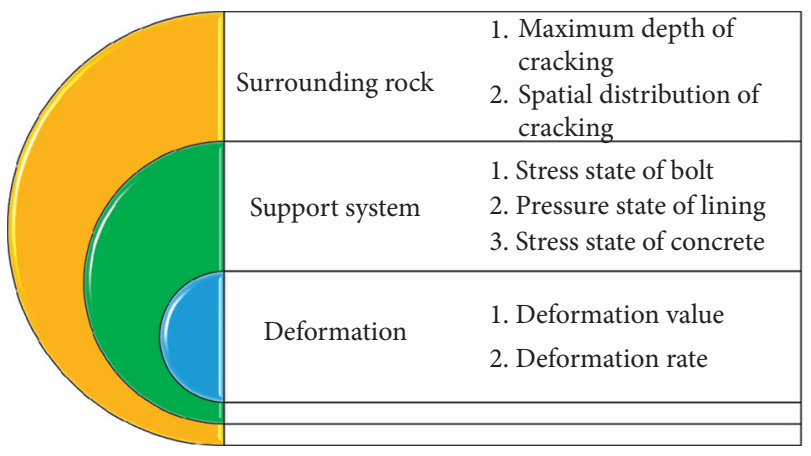

FIgURE 16: Multiple forms of warning information.

The specific parameters of the excavation process are the step size and step sequence, and these construction parameters can be optimized based on the monitoring data of surrounding rock. Parameters of the support system mainly include the bolt-mesh-shotcrete system parameters (length and spacing of rock bolt, thickness of shotcrete layer, and metal mesh measurements), grouting parameters (length and spacing), and lining parameters (thickness and strength). Support timing describes the sequence of the support system and the time to construct.

\section{Discussion}

Using the above-described monitoring data, the nonuniformity of shallow and deep cracks in the surrounding rock mass and the progressiveness of the aging displacement change can be observed. Excavation of the tunnel under high geostress induces cracking in a certain range around the tunnel, and stress redistribution may promote the gradual deepening of cracking. In this process, the gradual cracking of surrounding rock decreases its bearing capacity and shows the characteristics of aging deformation, as shown in Figure 18. Some locations, such as the bottom corner of the wall, exhibit large deformation (displacement far exceeds the overall deformation capacity of the bolt), but where a bolt has not failed, it may be because the bolt is parallel to the structural plane and moves with the surrounding rock. The mechanism of large deformation can be further studied by means of model tests or numerical simulation.

Different control measures can be selected based on the indexes of the evolution of cracking in the surrounding rock, considering the depth of the cracking area affected by excavation and the cracking degree of the surrounding rock. Monitoring the change of these two indexes can guide support design and evaluation. According to previous studies [22, 24], support parameters such as reasonable support depth and support timing will affect the development of internal cracks in surrounding rocks. As shown in Figure 19, the deformation coordination function of the first layer of the bolt-mesh-shotcrete system can be reasonably utilized to allow adjustment of the surrounding rock. The second layer of the support system, including bolt-mesh-shotcrete and grouting, can effectively strengthen the surrounding rock and restrain the development of cracking in surrounding rock for the control of large deformation. 


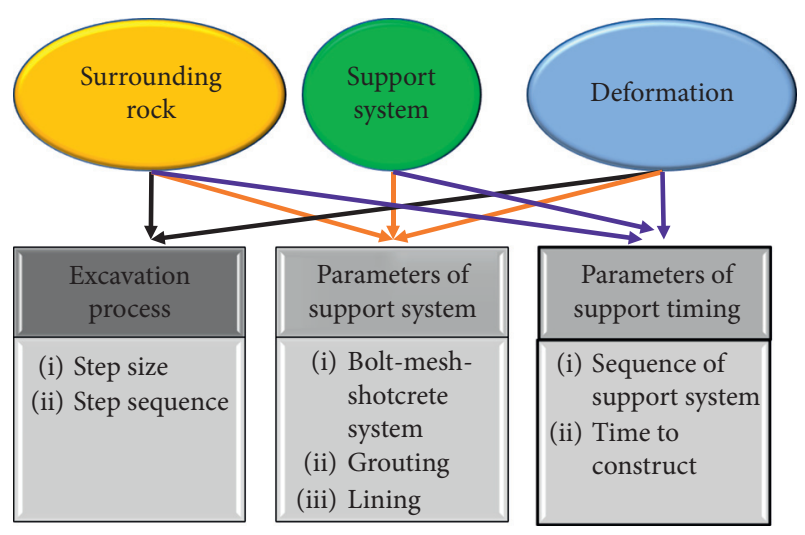

FIGURE 17: Monitoring information used to assess the risk of large deformation.

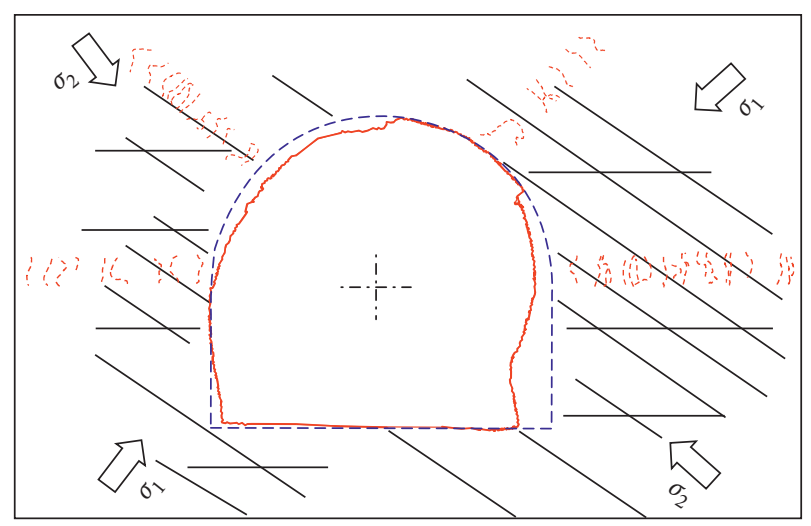

FIGURE 18: Preliminary mechanism of large deformation.

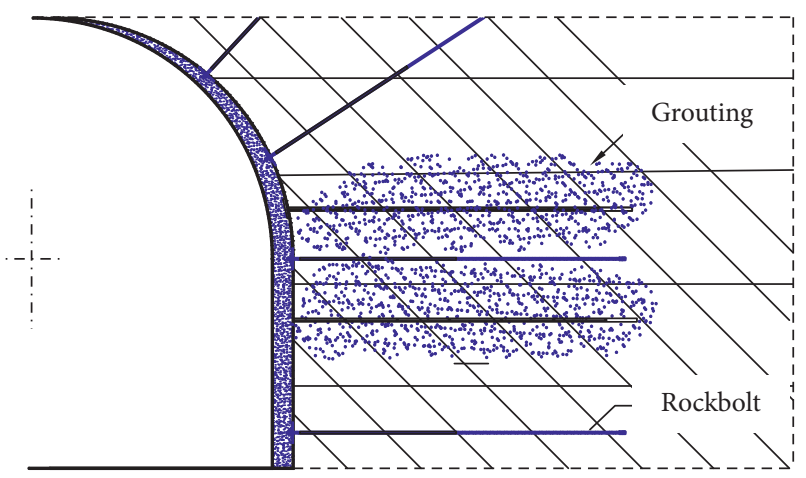

FIgURE 19: Schematic diagram of the support system.

Overall, to control large deformation, it is essential to predict large deformation and implement reasonable prevention and control measures. Prevention of large deformation requires comprehensive preparation at the design stage and the collection and use of geological monitoring data.

\section{Conclusion}

This work describes how to obtain real-time and three-dimensional information in a fractured hard rock tunnel to limit the risk of the development of large deformation. The collected information can guide engineering design and construction, provide early warning, and suggest effective control measures. The main conclusions of this work are summarized below.

(1) The use of a 3D, real-time monitoring system can capture the essence of a large deformation disaster. Evolution of large deformation can be analyzed by monitoring the deformation of surrounding rock, the dynamic process of rock cracking, and the pressure and internal stress of the surrounding support structure. Automatic data collection, realtime data transmission, and efficient data storage enable visual real-time display of the mechanical state of the surrounding rock and tunnel structure.

(2) A real-time warning and control module can be constructed to intelligently analyze data. The use of a three-dimensional monitoring system can detect the start of large deformation of surrounding rock, enabling the implementation of reasonable control measures. Based on tunnel service requirements, real-time monitoring data can be utilized for early warnings. Based on the warning information, data analysis can be carried out to propose the most appropriate control measures.

(3) The internal cracking of the surrounding rock is the fundamental cause of large deformation and cracking gradually expands to the interior. Observing the space-time relationship between support and large deformation should guide the strengthening of the support system. More attention should focus on the early restraint effect of rock bolt on the surrounding rock cracking, and rock bolt length should be extended when the cracking depth is insufficient.

\section{Data Availability}

The data used to support the findings of this study are available from the corresponding author upon request.

\section{Conflicts of Interest}

The authors declare that they have no conflicts of interest.

\section{Acknowledgments}

The authors gratefully acknowledge the financial support from the National Natural Science Foundation of China (no. 51621006) and National Key Research and Development Program of China (no. 2016YFC0600707). For their help, the authors also thank Professor Quan Jiang, Associate Professor Shuai Xu, Dr. Lei-Bo Song, and Dr. Jie Liu from the Shaoxing University, and Dr. Shan Zhong from the Institute of Rock and Soil Mechanics, Chinese Academy of Sciences.

\section{References}

[1] N. Barton, R. Lien, and J. Lunde, "Engineering classification of rock masses for the design of tunnel support," Rock Mechanics 
Felsmechanik Macanique des Roches, vol. 6, no. 4, pp. 189-236, 1974.

[2] Z. T. Bieniawski, Engineering Rock Mass Classifications, Wiley, New York, NY, USA, 1989.

[3] G. Barla, "Squeezing rocks in tunnels," ISRM News Journal, vol. 2, no. 3-4, pp. 44-49, 1995.

[4] K. Wang and F. Du, "Coal-gas compound dynamic disasters in China: a review," Process Safety and Environmental Protection, vol. 133, pp. 1-17, 2020.

[5] F. Du and K. Wang, "Unstable failure of gas-bearing coal-rock combination bodies: insights from physical experiments and numerical simulations," Process Safety and Environmental Protection, vol. 129, pp. 264-279, 2019.

[6] Ö. Aydan, T. Akagi, and T. Kawamoto, "The squeezing potential of rocks around tunnels; Theory and prediction," Rock Mechanics and Rock Engineering, vol. 26, no. 2, pp. 137-163, 1993.

[7] R. D. Dwivedi, M. Singh, M. N. Viladkar, and R. K. Goel, "Prediction of tunnel deformation in squeezing grounds," Engineering Geology, vol. 161, pp. 55-64, 2013.

[8] M. K. Panda, S. Mohanty, B. M. P. Pingua, and A. K. Mishra, "Engineering geological and geotechnical investigations along the head race tunnel in teesta stage-III hydroelectric project, India," Engineering Geology, vol. 181, pp. 297-308, 2014.

[9] W. Yu, W. Wang, X. Chen, and S. Du, "Field investigations of high stress soft surrounding rocks and deformation control," Journal of Rock Mechanics and Geotechnical Engineering, vol. 7, no. 4, pp. 421-433, 2015.

[10] Q. Jiang, S. Zhong, P.-Z. Pan, Y. Shi, H. Guo, and Y. Kou, "Observe the temporal evolution of deep tunnel's 3D deformation by $3 \mathrm{D}$ laser scanning in the jinchuan no. 2 mine," Tunnelling and Underground Space Technology, vol. 97, p. 103237, 2020.

[11] F. Ariznavarreta-Fernández, C. González-Palacio, A. MenéndezDíaz, and C. Ordoñez, "Measurement system with angular encoders for continuous monitoring of tunnel convergence," Tunnelling and Underground Space Technology, vol. 56, no. Jun, pp. 176-185, 2016.

[12] S. Mahdevari, S. R. Torabi, and M. Monjezi, "Application of artificial intelligence algorithms in predicting tunnel convergence to avoid TBM jamming phenomenon," International Journal of Rock Mechanics and Mining Sciences, vol. 55, pp. 33-44, 2012.

[13] P. Egger, "Design and construction aspects of deep tunnels (with particular emphasis on strain softening rocks)," Tunnelling and Underground Space Technology, vol. 15, no. 4, pp. 403-408, 2000.

[14] J. G. Zhou, H. L. Xiao, and W. W. Jiang, "Automatic subway tunnel displacement monitoring using robotic total station," Measurement, vol. 151, Article ID 107251, 2019.

[15] H. Song and P. H. Zhu, "Monitoring of tunnel excavation based on the fiber Bragg grating sensing technology," Measurement, vol. 169, Article ID 108334, 2020.

[16] H. P. Xie, "Research review of the state key research development program of China: deep rock mechanics and mining theory," Journal of China Coal Society, vol. 44, no. 5, pp. 1283-1305, 2019, in Chinese.

[17] M. Cai and H. Peng, "Advance of in-situ stress measurement in China," Journal of Rock Mechanics and Geotechnical Engineering, vol. 3, no. 4, pp. 373-384, 2011.

[18] M. F. Cai, L. Qiao, C. Li, B. Yu, and S. Wang, "Results of in situ stress measurements and their application to mining design at five Chinese metal mines," International Journal of Rock Mechanics and Mining Sciences, vol. 37, pp. 509-515, 2000.
[19] R.-H. Cao, P. Cao, and H. Lin, "A kind of control technology for squeezing failure in deep roadways: a case study," Geomatics, Natural Hazards and Risk, vol. 8, no. 2, pp. 1715-1729, 2017.

[20] X. L. Feng, F. S. Ma, and H. J. Zhao, "Deformation, failure and analysis of convergence monitoring of rock mass in deep high-stress and swelling roadway," Journal of Engineering Geology, vol. 26, pp. 716-723, 2018, in Chinese.

[21] Q. Jiang, X. T. Feng, S. J. Li, G. S. SU, and Y. X. Xiao, "Cracking-restraint design method for large underground caverns with hard rock under high geostress condition and its practical application," China Journal of Rock Mechanics and Engineering, vol. 38, no. 6, pp. 1081-1101, 2019, in Chinese.

[22] Y. Zhang, X. T. Feng, X. X. Zhang, Z. F. Wang, M. Sharifzadeh, and C. X. Yang, "A novel application of strain energy for fracturing process analysis of hard rock under true triaxial compression," Rock Mechanics and Rock Engineering, vol. 52, no. 2, pp. 1-16, 2019.

[23] T. Chen, X.-T. Feng, G. Cui, Y. Tan, and Z. Pan, "Experimental study of permeability change of organic-rich gas shales under high effective stress," Journal of Natural Gas Science and Engineering, vol. 64, pp. 1-14, 2019.

[24] X. T. Feng, X. J. Hao, Q. Jiang, S. J. Li, and J. A. Hudson, "Rock cracking indices for improved tunnel support design: a case study for columnar jointed rock masses," Rock Mechanics and Rock Engineering, vol. 49, pp. 2115-2130, 2016. 